\title{
Language Situation in Post-War Sudan
}

\author{
Dr. Ahmed Gumaa Siddiek \\ King Saud University - KSA \\ E-mail: aahmedgumaa@yahoo.com
}

\begin{abstract}
The theme behind this paper is to review the language policy and language planning in the Sudan, after the institutionalization of peace; by exploring the recent policy of political factions in the North and the South towards languages in post-war Sudan. This effort aims at encouraging non-Arabic speaking-ethnic-groups to accept the Arabic language as lingua franca, by allowing it an official status in education and government offices. The paper also aims at encouraging the Arabic speaking majority in the North, to take the initiative to study and learn the most dominant local Sudanese-African languages, and be familiar with their oral and written literature; as well as realizing the role of these languages in enriching the cultural heritage in our country and making unity an attractive choice.
\end{abstract}

Keywords: Language planning, Language policy, Lingua franca, Local languages, Language education

\section{Introduction}

Language policy and language planning is one of the thorniest issues that often face nations in their historical and social development. The issue also remains as a big challenge for the ones who want to rule. In this paper I want to tackle the subject from another point of view, that is the Arabic language should not be seen in the religious context as most of the Muslim scholars and Arabic language speakers always entwine between Islam and Arabic. Islam is a religion which can also be adopted by non-Arabic speakers all over the globe, while Arabic is a language which is spoken by Non-Muslim Arabs such as the Arab Jews and the Arab Christians.

The research also aims at encouraging the Arabic speaking majority in the North, to be positive and initiative to study and learn the most dominant local Sudanese-African languages and be familiar with their oral and written literature; as well as realizing the role of these languages in enriching the cultural mosaics in our country. Multiculturalism is a global phenomenon in most of the modern societies today. The Sudanese people speak more than 560 local languages. Some of these languages are spoken by a handful of people and some are spoken by millions of people such as the Dinka, Neuer and Shulk. But Arabic is the most dominant as it is spoken by the majority as mother tongue and also spoken with different variations in many places as a second language. Arabic is an integrating social and political factor in the unity of people of the Sudan. Some local languages are adopting the Arabic alphabet and some of the Biblical Scriptures are written in Arabic as. So, if it is the situation of Arabic there, what is the problem then?

\section{Statement of the problem}

The problem is that, Arabic is losing grounds due to some orientations of some political groups in Southern Sudan, who are working hard to deprive this language the official status in the government offices and education. This negative attitude may be due to search of identity from one side, or it may be a mere reaction to the unfavourable history of Arab practices in the South from one side. It may also be due to the connection between Arabic and Islam which is not fully welcomed among some Southerners with Christian background. Of course it is my belief that every people have the right to choose for themselves the language of their communication and adopt freely their religious beliefs, but Iam here to - just - remind with the benefits that can be gained by both people in the North and the South, if they could manage to establish a lingua franca that can facilitate easy communication between them in the different regions of our country; and consequently maintain living in one united country. I do not need to mention that both people in the North and the South share many economic interests. The rich tropical products in the South do always find their way to consumers in the markets of the North; as these products are practically unmarketable in the African countries neighbouring Southern Sudan, because these countries produce the same tropical products. However, these commodities are highly demanded in Northern Sudan, the rich Arab world, North Africa, Europe and Asia. The economy of Southern Sudan can benefit from the infrastructure that already exists in the North; to facilitate easy access to highly populated consuming markets. The trade of the South will need to migrate northwards via the North of Sudan to find passage to the demanding rich Arab world, Europe and Asia through the Swiss Canal, and to Asia through Port Sudan on the Red Sea Coast. Migration to the North seems to be a fate, for very simple reason, that the South has to defend its trade and other socio-political interests in the north hemisphere. 
This work also encourages the education of local languages \& local literature, because this will pave the way for a unified Sudan through interaction and mutual understanding.

\subsection{The Significance of this Research:}

This paper addresses the language issue and aims at speaking directly to the policy makers, educators, teachers as well as individual persons to consider the issue of language in the country. We aim to establish a common language to be used by all Sudanese, as well as trying to convince the Arabic speakers to show positive attitudes towards non-Arabic speaking groups, by respecting their languages and recognizing their wisdom through their literary creative production which can add to the diversity and the rich mosaic of our culture.

\section{Languages in Africa}

Languages are means of exchange for feelings and ideas. They are also tools for the handling of services and interests between individuals and communities. The language education is a big concern of individuals and communities now, in such a fast changing competitive global economy. Languages have always been unifying factors among human beings, but they were sometimes elements of conflict and discord. Natural barriers such as waters, mountains and deserts were and still are strong language barriers between people, but man through history has invented many tricks to overcome these barriers by practical means such as translation and interpretation. But language teaching and learning will remain the most effective ways for human beings to establish positive communication. The search and identification of identity of one specific people by speaking one specific language is one of the major language barriers but still this is the people's own choice. The world today speaks thousands of languages. Some of them are about to be extinct. It is a pity to realize that some local languages are disappearing now in the Sudan such as the (Anag which is an old Merwoen language). Iam also very sad to learn that, there is one local language (Gulli) is spoken by only four people now, while a language (Haraza) in Western Sudan has been extinct because the last speaker passed away some years ago, AlKhalifa, et el (2006:99). But some languages are dominant and spoken by millions of people for historical, geographical or ecological reasons.

The demographic facts about the language ecology of Africa With approximately 2500 languages (or 30 per cent of the world's living languages) is something that deserves some care. Africa is one of the most linguistically diverse continents (Adegbija, 1994; Grimes, 2000; Batibo, 2005). However, Africa's language resources and their place in African development are unrecognized and little documented or researched in the context of African Studies. Language study according to Ndhlovu (2008) currently exists on the periphery of mainstream African Studies teaching and research activities. Most of the existing African Studies Programs are mainly underpinned by approaches drawn from such disciplines as history, economics, sociology and anthropology. Ndhlovu (2008) mentions that there are two diametrically opposed perspectives have emerged in relation to the presence of many languages in Africa. The first perspective is one that views the existence of many languages in negative light, associating them with all sorts of problems including ethnic conflicts, political tensions, poverty and underdevelopment. He quotes (Zeleza, 2006: 20) that for this school of thought the multiplicity of African languages is often seen as a bane of African unity, whether at the national, regional or continental level. Multilingualism is thus seen as a liability and a burden, particularly when considered in the context of the amount of resources needed to promote the use of multiple languages in the domains of education, media, law and administration, business and commerce and international communication.

\subsection{Sudan in Africa}

Languages issue in the Sudan can be seen in that context. The economy and education in Southern Sudan can benefit from the infrastructure already exits in Northern Sudan. The trade of the South will need to migrate northwards to reach the demanding markets in Asia and Europe. The North of the Sudan as Arabic speaking agent can help to play this role of intermediary to link Southern Sudan with the Arab world through education and trade. Migration northward can be seen advisable, if we can just contemplate on the results of last political clashes that took place in one neighboring country bordering the Southern region in the south. Those clashes gave solid evidences that Southern Sudan had severely been affected by the events in that neighboring country; and might be affected again by such incidents in the future. Those events made the Southern region practically a blocked inland area, as the Southern region does not have sea harbours. Due to those clashes the prices soured up in very short time, with severe shortage in food, energy, medicine and other commodities. This unpleasant incident has given clues that Southern Sudan is fated to northwards migration in both cases: of achieving political unity with the North or in case of cessation to establish an independent African State. But unity should be our goal but what grounds do we think can make this unity an attractive choice?

\subsection{All Losers}

The future of the Sudan is at stake due to the prevailing disputes between the two political factions, who signed 
the Niavasha Comprehensive Peace Agreement (CPA) in 2005. The future of the Sudan is really dubious, but some efforts from all Sudanese including the academic personnel may soothe the political tension and help the decision makers to think over the future of our Sudanese Nation. This paper is one attempt as the writer as an academic person can provide his advice from linguistic point of view.

The writer believes that the Sudan should remain united through speaking one language to make unity an attractive option for Sudanese in the South and the North. The language is a welding agent and an integrating element of unity among any people in the world, as language is the conveyer of feelings and ideas from one person to another and from community to community. Ethnic diversity, multi-culture and multilingualism should not be a cause of differences and conflict between the two peoples.

Cessation - although remains the people's own choice- but I think it is not such a bright idea because it will weaken both partners in the South and the North simultaneously. Let us now make the following calculations by trying to answer the following question:

- What would happen if the people in the South decided separation from the motherland?

- What are the people in the North going to lose if cessation took place?

- What is the Sudan going to lose if this happened and a new independent state is born in the South?

\section{a. Cessation is not that inviting idea for the Southerners because:-}

- The South will miss its share in the already existing infra-structure in the North.

- It will reduce the role of the South as an agent of pressure to secure the rights of the other suppressed \& marginalized Sudanese minorities.

- The South will be deprived from the North as the gate to the Arab world.

- It will be deprived from the use of the national ports on the Red Sea, the national airports in the mainland and from the domestic ports in Kosti and the other harbours on the White Nile.

- It will be deprived from the Northern markets for its tropical products.

- The cessation will help the eruption of tribalism in the South. (It did practically begin and many souls are lost)

- The South will have to share the burden of the international debits against the Sudan.

\section{b. Cessation is not a good choice for the Northern Sudan because:}

- The northern nomad herdsmen will be deprived from the pasture in their usual summer march into the southern regions for grazing their herds.

- It will stop the development of the River Nile Projects.

- It will deprive the North from the markets of the East African States.

- It will deprive the northern products from markets in the southern region.

- The North will be the biggest loser because; it will be warded off the oil in the region.

- Cessation will hold back the development of the Savanna animal and agricultural belt in the joint regions. Al-Mahdi (1993)

\section{c. The Sudan}

- The Sudan will be the biggest loser because a third of its population and a third of the land will be lost for ever.

- It will close down the role of the Sudan as a bridge between Africa and the Arab World.

- Islamic minorities may face some difficulties in educational and social integrity.

\subsection{Multiculturalism \& Multilingualism in the Sudan}

Sudan is a multicultural and multilingual country. We can Just contemplate on the following data: The population of the Sudan according to the ethnic census of 1956 gives us the following data that: the population of Sudan was consisted of: $39 \%$ Arabs, 30\% Southerners, $13 \%$ Westerners, $6 \%$ each of Bejja and Nuba $3 \%$ Nubian, $3 \%$ Foreigners \& Miscellaneous. These percentages were based on the identification of tribes (of which 597 were registered, grouped into 56 tribal major groups). In the census people could choose which tribe under which to register themselves, but the tribes themselves were categorized by the census as Arab, Southern, Western, Bejja, Nuba, and Nubiyin (Nubian). Of course this was inadequate but remains the only ethnic census taken. The census 
determined that Arabic was spoken at home by $51 \%$ of the population.

According to Jernud (1979), 90\% of the parents spoke Arabic in the North, while $40 \%$ speak Arabic in the South, but Arabic is used as Lingua Franca between all tribes who speak different local languages. In his study, Jerund found that, the children of 324 families out of 372 married couples (91\%) were speaking Arabic as their first language. In another study he found out that out of 414 people in Nuba Mountain who spoke five languages: Arabic, Deling, Aldaier, Tawaleesh and Bango, (99.3\%) spoke Arabic. He also found that, in Kordofan out of 174 people 150 (86.2\%) spoke Arabic.

Arabic according to Scholl (2008) was first introduced in the South during the Turco-Egyptian rule, which established the first official and administrative contact between the North and the South. This enabled a group of Arab and European traders, explorers and missionaries to come to the area. Formal education was introduced in the South in 1901, when the first primary school was established. It spread through the interaction between the Northerners-who went there as traders- with the Southern tribes, in addition to the physical contact between some of these tribes such as Shiluk and Dinka - using pidgins (Nilotic Arabic.) with Arabic speaking tribes of Darfur and Kordofan. Arabic vernacular is now spoken by $70 \%$ of the people in the South, while English is spoken by only $8 \%$ of the people, Al-Faki (2009)

\subsection{Colonial Era}

Arabic had been in continuous conflict with English in the South. Bishop Gwynne of the Church Missionary Society (1910) wrote that, "if the government would as far as possible encourage the use of English as the medium through which the business with the native could be transmitted, it would be an inducement on the part of the native to learn our language and would give Christian missionaries some slight chance over the overwhelming advantages, which Islam seems to have at present in Southern Sudan. Baraka (1984. 114)

This showed that the spread of Arabic was connected with the spread of Islam, as well as was English entwined with Christianity. This language policy towards introducing English to replace Arabic was culminated in the 'Memorandum on Southern Policy in 1930 emphasizing that officials should avoid the error of thinking that by speaking Arabic they are in some way confronting to the principles that administrators should converse with these people in their own language" But despite all those efforts to institutionalize English, the Governor General lamented by saying in (1927) that "I have fully appreciated the difficulties of ever making English the lingua franca of the South. Things have gone much further than I had expected. Whenever I penetrated to the top of the Imatong or the Belgium Congo border, I found Arabic in ready use by the local spokesmen of the people. I need not enumerate the main causes which have operated to produce this result ...we have to consider the very carefully how far it is worth effort and money to aim at the complete suppression of Arabic." ibid (1984:119).

It was interesting that the Governor General came to see the fact as he said, "....indeed we shall have to consider whether Arabic after all, in spite of its risk, must not be our instrument. The opinion I have here expressed is strongly held in the South. Even at remote Lui, Dr. Fraser put on the same view. Captain Kid at Shambe told me that he had sent 54 boys to Malek Mission and they all came talking Arabic although the Archdeacon is very definitely hostile to that language." Ibid (1984:120).

We could understand from this, Arabic was able to found good grounds and English failed to be the medium of education. This dilemma made Mr. Hussey (then Chief Inspector) to call for an urgent meeting to discus the necessity for an authoritative language conference, as soon as possible and recommend that Sudan Government should take steps to initiate such a conference. ibid (1984:122). Hussey recommended the cooperation with the International institute of African Languages and Culture. So as it was an urgent matter, the Government of the Sudan obtained the services of professor Westermann, who was one of the directors of the International Institute as an expert and advisor. An inter-territorial Conference was convened as a result in Rejaf in 1928 and came out to oppose Arabic and adopted English as lingua franca in the South, and with the assistance of professor Westermann the conference made a list of six local languages for educational purposes, included Bari, Dinka, Nuer, Shiluk, Lutho and Zande. The conference also laid the foundation standard orthography named as Rejaf Orthography for the writing of these languages.

Then Dr.Tucker-linguist expert-was engaged in the production of textbooks, grammar and vocabularies of the selected languages. But his efforts failed as he put it, "My chief difficulties encountered in all languages were the fact that very few missionaries or language authorities assimilated the Rejaf spelling system." Sanderson (1984:112). Other problems rose from the fact that some of those languages were spoken by small minorities.

Arabic - though it was written in Latin characters - was still a problem according the Civil Secretary who wrote in 1929 that, "The Mission realizes that the whole question of Arabic is still not settled. It is a great pity that we 
cannot go ahead though the school has the best teachers. The mission fathers themselves would like to give up Arabic but there are grave doubts whether any other language is practicable in Wau at present." Baraka (1984:124)

Arabic then was able to establish good grounds since the contact between the natives and the Arab traders was continuous and active. This problem made the civil Secretary issue a famous Memorandum clearly stated that officials should avoid speaking Arabic. They should converse with the people in their own language, and that an official who was unable to speak the local vernacular should try to use English when speaking to the Government employees and servants and even, if in any way possible, to chiefs and natives. In any case the use of interpreter is preferable to the use of Arabic, until the local language can be used." Baraka (1984:126)

This failure of educational system resulted in growing demand for Northerners employed in the South and communication between the North and the South being developed. The application of this policy broke down the previous isolation of the South and rendered it advisable that the policy of the 1930s should be revised.

The government in the South came to understand the fact that, "the people of the Southern Sudan are distinctively African and Negroid, but that geography and economy combine to render them inextricable bound for future development to the Middle-Eastern and Arabicised Northern Sudan: and therefore to ensure that they should by educational and economic development, be equipped to stand up for themselves in the future as socially and economically the equals of their partners in the Sudan of the future. This new policy raised the question of languages once again so in his memorandum on the South Policy in 1946, the Civil Secretary declared that,"...in Education, I believe while the South may hope to have a secondary school, it cannot hope to support post-secondary education, and I believe that Southerners should get this at Gordon Memorial CollegeArabic is not essential there, but should I think be taught to southerners as a subject from the intermediate school level upwards.

Consequently, the Governor- General authorized in 1949 the directive that Arabic should become the common language of the south. This was endorsed by the Legislative assembly in November 1949, when the Minster of Education addressed the Assembly by saying that, “....as the Sudan is one country sharing the one set of political institutions, it is of great importance that there should be one language which is understood by all citizens. The language can only be Arabic, and Arabic must therefore be taught in all our schools." ibid (1984:.133). As an immediate result to this, Mr. Griffiths (the Principal of Bakhet-Erudha) was sent to the South to develop a plan for the training of southerners in the teaching of Arabic. In 1951 a five-year plan (1951-1956) was adopted to expand and improve the educational system in the South by the assimilation of method of teacher training, the use of similar textbooks, the adoption of common syllabus and the introduction of Arabic above the village school level Practical steps were taken to enable southern teachers to speak and teach Arabic, a secondary one-year Arabic course at Delling elementary Teachers' Training College was provided for Rumbek secondary school prior to there entry to Bakhet-Erudha Intermediate Training College. The experimental work on the Arabic syllabuses was conducted in the closet liaison with Rudha Institute and a quarterly magazine in Arabic and English was produced for the educated southerners to help spread Arabic. It was planned that Arabic literacy campaigns be started by trained staff in the most populated area.

\subsection{Arabic \& Islam}

The educated Southerners began to look at these new developments as new-Northern cultural imposition opening the way to Islam and Arabic culture; so it came to failure despite the fact that a good intention from the government side was unmistakably noticeable. Basheer (1984:157) explains this by saying that: "The Southern educated class - themselves products of missionary schools, suspected that the aim of the Northerners was to spread Islam and Arabic culture." However, there was some truth in this perception, but only some, and that being the definite relation between the Arabic language and Islam; things did not go as it was planned. But negative attitudes were still held by some northerners that in many Southern schools any student who knew Arabic well and scored high marks continuously teased by other students and labeled 'Arab' even if he were not suspected of sympathizing with Northerners. Basheer (1984:157)

\section{From Addis Ababa (1972) to Niavasha (2005)}

In (1972) the two factions in the North and the South were able to come to a peace agreement signed in Addis Ababa by Joseph Lago the leader of (the Anyanya) and Numairi, the president of the Democratic Republic of the Sudan, then. The agreement recognized the self-government for the Southern region. In respect to the language policy, Arabic was named as the official language in the country while English was considered as the principal language in the South. The Self-Government Act discussed the language issue in Chapter ii, Section V that, "Arabic shall be the official language for the Sudan and English as the principal language in the South as a 
working language, as matter of convince in order to meet the aspiration of the people of the region and to ensure the efficient running of the region in all its departments and units. Local languages shall be encouraged for the following reasons: (a) to serve as the practical need of the discharge of duties in day-to-day business. (b) for the promotion of patterns of culture of the people of the region.

In (1972) the first educational conference was convened in Juba in July where the regional Minister of Education appealed to the conference to tackle the language problem in Southern Sudan schools from the merely educational point of view and not to be influenced by the past political attitude towards Arabic, for he believed that the Addis Ababa Accord had removed all the worries and misunderstanding between North and South. The Juba conference came out after long debate in language with the following that, if the teaching of the tribal languages is introduced right from the first year primary for any period as medium of instruction whereas Arabic be introduced from the same age as a subject, Southern pupils will be put in a disadvantageous position with their counterparts in the North in National Certificate Examinations, but as a political expedient, the teaching of these languages should be introduced, and ways for their teaching could be found.

The issue of language was finally solved by the Executive Council Resolution as it had been decided that in the future, in rural areas, the first two years of teaching should be in local languages, after which teaching should be mostly in Arabic. Also special arrangements were taken to tackle the question of language for the children who had their instructions in English and French, where large schools may have a class learning in Arabic and English was to be taught as a subject.

This was finally decided by a resolutions from the Assembly in 1974, that "English language be re-introduced as the medium of instructions in the educational institutions of the Region as from (1974/1975) academic year but this resolution was rejected by the Executive Council which recommended a language policy clear and precise that:

a) in rural schools

i) The vernacular be used as medium of instruction in the first and the second years with Arabic and English introduced orally.

ii) The vernacular be used as a medium of instruction in third and fourth years while Arabic and English are intensified.

iii) Arabic be medium of instruction in the fifth and sixth years while English continue to be intensified.

b) in the case of Urban schools

i) Arabic shall be the medium of instructions in the first and second years while English is introduced orally.

ii) Arabic continues as medium of instructions in third and fourth years while English is intruded in writing.

iii) In the fifth and sixth years Arabic contuses as medium of instruction while English is intensified.

c) In all junior secondary [intermediate] schools: Arabic shall be the medium of instruction while English is intensified.

d) In all senior secondary and post senior secondary school, English shall be the medium of instruction and Arabic is taught as a language with its literature.

e. Adult education shall be conducted in local languages and Arabic. Baraka, (1984:163)

\subsection{New Generation}

The Sudan witnessed the longest civil warfare in Africa. It erupted in Aug. $17^{\text {th }} 1955$ following the mutiny by the military of the Equatoria Army Division. During successive periods from 1955-1972, 1983-2003 the toll was totaling 2 million dead, along with uncountable number of injured and disabled. Many lives were lost because of war and war related famine. The number of lost people was bigger than the total number of the lost souls in the Bosnian, Rwandan and Somalia wars combined, as stated by Dr. Garang in his address to the (United Nations Human Rights Commission in Geneva on March, 24 1999.)

Nevertheless, Sudan exerted many efforts since independence to stop the civil war. The first attempt was the Round table Conference in May 1965. Another conference was in March 1972, between Nimmairi and Joseph Lago of the Anyanya, but it failed and paved the way to another mutiny in 1982 by the (SPLM) under the leadership of Dr. John Garang De Mabyor, who lately signed on the $20^{\text {th }}$ June 2005 the recent Comprehensive Peace Agreement (CPA), with the Vice President of the Sudan Ali Othman M.Taha, in Kenya. The efforts were under the sponsorship of IGAD, USA, and other European partners. They successfully ended the longest war in Africa if not the longest civil war ever known in the human history. The war erupted and continued to 
accumulate hardships on everybody in the community. It did affect the life of millions of people by death or displacement. Children lost their parents; others had to share the suffrage either: physically by being recruited as young fighters in the jungle or psychologically by losing interest in education. A few lucky children had the chance of education in refugees' camps, with different culture and different educational environments in another language rather than his mother tongue. These experiences left these young learners with great physical harm and psychological pain, a thing that will need immediate rehabilitation programmes for most of them. We have to start giving them instructions in their own local languages, as it was recommended by the UNSECO to establish good intimacy between the child and his local environment. To do this (GoSS) decided to recruit English teachers from two neighbouring countries - as came in the news of July 6, 2006 from that-about 130 foreign teachers were coming to teach in Southern Sudan with more than 60 others expected to leave the country to the vast region. (www.Sudanvision:2006).

This educational policy will once again alienate these children from their local culture and traditions. This can be supported by a story from The Washington Post correspondent who reported from the Nuba Mountains, by telling the story of a Nuba boy in his new school. She said that the people of Nuba, through centuries of slave trading and forced migration, speak Arabic, the official language of Sudan. But they say they are closer ethnically and culturally to the south, where English became commonly used when the region was under British control.

But this is not absolutely the truth. The Nuba came to speak Arabic through the natural interaction with the Arabic speaking tribes neighbouring their regions in Kordofan and where they practiced Arabic in their prayers as Muslims which was their own choice as religion. The Nuba boys and girls can be taught in the local language and be exposed to Arabic as it is familiar in their homes, where it is used by their parents and their neighbours in different local variations. We can refer to one study in Haiban - a Nuba region in Kordofan- where it gave evidences of Arabic spoken by about (86.2\%) of the people. It is here to mention that Nigeria according to Cyffer (2006:21) had once adopted the English language in its primary education but after a long time the experience proved a failure and they got back to instruct children in their own local tongues. The concept of "straight for English in primary education was considered a failure. Therefore the new motto became 'a child learns better best in his local language.' Luckily this new trend is encouraged by the (CPA) which approved of a language policy in the Niavasha protocols where in addition to Arabic and English, the legislature in any sub-national level of government may adopt any other national language(s) as additional official working language(s) for the locality.

\subsection{Niavasha and the language issue}

The war - as we know - once again erupted in 1982 and happily quenched in 2005 by the agreement of Niavasha's protocols, signed by the government of the Sudan (GoSS) and the (SPLM) in Kenya, to end the war. In the protocol of power sharing signed on $26^{\text {th }}$ May, 2006 by the two factions, they included the language issue in article No. 2.8. (Akhbar Al-Youm Book Series, 2004)

In this protocol, article 2.8.4-which reads, (In addition to Arabic and English, the legislature of any sub-national; level of government may adopt any other national language(s) as additional official working language(s) at its level). It is clear that autonomous decisions can be easily made at the local government level to freely choose the language of interaction in its government and educational institutions. This is the legislative reason that let the government of Southern Sudan (GoSS) to adopt English as the official language and means of instruction in the South effective from 2007. Children will go to school to new language environment where English is going to be taught from the very start at the basic school level.

But due to the long war the infrastructure in the South needs to be reconstructed including the school environment. There is severe shortage of school buildings, teachers, textbooks and teaching aids. There is severe shortage of trained teachers in all fields and in English in particular; a thing that made the Regional Ministry of Education to recruit teachers from some neighbouring countries to fill the gap and keep the educational machine go. This recruitment of staff will definitely have its negative results socially, economically and politically. Socially, these teachers will come to the country with foreign habits that may contradict the habits of the people in the South. Economically, these teachers will be paid in hard currency and with salaries that the budget in the South cannot afford. So, the shift from Arabic to English is very costly where the contracted teacher will be paid 300 dollars as salary plus 90 dollars as meal allowance and 190 dollars for accommodation. With such an amount of money (GoSS) can afford recruitment of teachers from local native staff from the North, well trained to teach Arabic and can also train teachers from the Southerners themselves. Arabic is a welding factor among these tribes as stated by Riak Gai (2007:122) who sees Arabic as one of welding elements that willingly joins the tribes 
of the South together. (Juba Arabic) which is a hybrid variety of Arabic is widely spoken by most tribes in the south with different variations. Most of the elites in the South speak Arabic as fluently as any Arabic speaker from the North. It is here to mention that learning Arabic was encouraged by effective people such as Dr. Garang as reported by Khatir (2006). He himself was an eloquent speaker although he used simple Arabic to express the most difficult political and ideological concepts. He used to encourage his leaders to master the Arabic language. He used to talk to his military forces in Juba Arabic. This Juba Arabic was also used by the SLPM/A Radio in Ethiopia and it is still the language of transmission in Juba. It is spoken by more than $75 \%$ of the people in the South while English is spoken by only $8 \%$, Al-Faki: (2007)

\subsection{The Claim \& the Flame}

Arabic could have been finally established as Lingua Franca in the South, had not been frequently associated with negative practices of the 'Galaba' of the North, in their envelopment in slave trade as mentioned by Dr. Scholl (2005:22) who said that the term Galaba had negative connotations in the minds of the Southerners, as it was always associated with bad practices of Northerners in that notorious trade. This is one of the most serious psychological barriers that underline the socio-political relation between the North and the South. It is time for the people in the South and the North to go over this moment in similar reconciliation and self redeem practices that took place in South Africa after the abolishment of apartheid regime. It is the truth that all Sudanese are African by definition. This is due to the undeniable factor of geography in constituting our African pigmentation, African features, African temper and African mood. I think it is high time to realize and deny those fallacies of racial claims which have flared up the fire of racial and political disputes all over the country with those long civil wars. The genealogical claim of belonging to Arab ethnicity was the cause behind the civil wars in the South and still the cause of war in Darfur. It is true that the majority of our people in the Sudan speak Arabic, however, it does not stand as a symbol of racial identity, but Arabic is a mere culture similar to the situations of Latin American races or Afro-Americans who live in English, French or Spanish speaking communities but they adopt the cultures of those communities that hosted them. Those people speak those languages, but they maintain their African or Latin identity at the same time.

\section{Conclusion}

If we recognize Arabic as a mere sort of culture and not an ethnicity associated with false claims; I think this would reduce the tension of racial disputes in our country and encourage others to form positive attitudes towards our language and willingly assimilate our culture. Iam here to refer to Dr. Al-Bagir Al-Afifi's daring paper entitled "The Crisis of Identity in Northern Sudan: A Dilemma of a Black people with a White Culture" But In spite of all the ecological, political and social difficulty, Arabic survived and "...it is there to stay" as stated by Mr. Edward B. Mandeson from Indiana University in his letter on 15/12/1984 to Dr.Tamimmi where he said that: "My contention given the historical experience for the South and the background history of the Sudanese nation with its diverse national character, the Arabic language has come to stay and all that is needed is the casting of an agreeable language policy which is devoid of the historical sensitivities, generated by the traumatic historical experience the Sudan has gone through, is the only way out." Yes, it is "there to stay" but of course -this time- by the own free will and choice of the people.

\section{References}

Al-Afifi, Bagher. (2009). The Crisis of Identity in Northern Sudan: A Dilemma of a Black people with a White Culture", presented to the CODSRIA African Humanities Institute. Tenured by the Program of African Studies at the Northwestern University, Evanston. USA.

Abu Managa, Alamin. et tel. (2005:121). Languages in Africa, (in Arabic). International University of Africa Printing Press. Khartoum.

Adegbija, E. (1994). Language Attitudes in Sub-Saharan Africa: A Sociolinguistic Overview. Clevedon, Philadelphia and Adelaide: Multilingual Matters. Alexander, N. 2005.

Al-Faki, M. Mohammed. (2007). The Influence of Arabic in the Identification of Sudanese Nation. A paper presented in the symposium of the Scientific Council of Arabic Language. Omdurman. [in Arabic ].

Akhbar Al-Youm Book Series. ( 2004). Draft of Final and Comprehensive Peace Agreement In Sudan. An unofficial Translation of the six Protocols signed by the Sudanese Government and the SPLA. First Issue. (P, 82) July 2004. Khartoum.

AlKhalifa,Yousif, et el. (2006). Languages of Africa, (in Arabic). International University of Africa Printing Press. Khartoum . 
Al-Mahdi, Asadiq. (1993). Political Destiny of Southern Sudan. A paper by the Foreign Bureau of Publication in the Oma's Party [in Arabic].

Baraka, M.Z. (1984:112). Language in Education and Policy. A Sudanese case. Unpublished PhD thesis. Department of education, University of Wales.

Basheer. M. Omar. (1984) Educational Development. In Baraka, M. Z: (1984:112). Language in Education and Policy. A Sudanese case. Unpublished PhD thesis. Department of education, University of Wales.

Batibo, H.M. (2005). Language Decline and Death in Africa: Causes, Consequences and Challenges. Clevedon: Multilingual Matters.

Cyffer, Norbert. (2006) A study of African languages. Dirasat Afriqiyya Periodical issue 35, June 2006 [in Arabic] .

Crystal, D.(1996). The Cambridge Encyclopedia of Language. Cambridge, Cambridge University Press.UK.

Douglas, Karol, Josef Krotki. (2004). Demographic Survey of Sudan, in The Population of Sudan. Report on the Sixth Annual Conference (Khartoum, Philosophical Society of Sudan, (1958) [a digest of the first census's findings], pp.36-7.

Gaha Allah. M. Kamal. (2007). Foreign Languages in Africa. Research \& Studies of Middle \& Africa. Issue No. 5, periodical [in Arabic]-Khartoum.

Grimes, B.F. (2000). Ethnologue: Languages of the World, Volumes 1 and 2. 14th Edition. Dallas: SIL International.

Jernud. (1979). In Tammimi. Arabic Language in the Sudanese Model Community. [In Arabic]. Omdurman University Printing Press. Khartoum.

Khatir, Abdullah Adam. (2006). Al-Sudani Newspaper, Wednesday 2 August.

Ndhlovu, Finex. (2008). Language and African Development: Theoretical Reflections on the Place of Languages in African Studies. Nordic Journal of African Studies 17(2): 137-151.

Riak Gai: (2007). Janoob Alsoudan in Arabic - Oman- Jordan.

Sanderson and Sanderson. (1984). In Baraka, M.Z: (1984) Language in Education and Policy. A Sudanese case. Unpublished PhD thesis. Department of education, University of Wales.

Scholl, Pual Deng. (2005). Juba Arabic. Adar Asoudania for Publishing. Khartoum.

Tammimi, A. Omar. (1997). Arabic Language in the Sudanese Model Community.[ In Arabic]. Omdurman University Printing Press. Sudan.

Wax, Emily, (2009). Newspaper Report from Nuba Mountains for the Washingtonpost. www.sudanvision.com.

Zeleza, P.T. (2006).The Inventions of African Identities and Languages: The Discursive and Developmental Implications. Selected Proceedings of the $36^{\text {th }}$ Conference on African Linguistics, pp. 14-26. Somerville, MA: Cascadilla Proceedings Project. 